\title{
The Work Ethic and Social Change in the Czech Republic and Slovakia - A Modernisation Theory Perspective*
}

\author{
MICHAL KOZÁK** \\ University of Bergen
}

\begin{abstract}
The article investigates long-term trends in the work ethic in the Czech Republic and Slovakia from the perspective of modernisation theory. In particular, it examines whether the work ethic in the two culturally similar societies decreased during the years of growing material prosperity and whether this trend originated in intergenerational population replacement. The study uses data from three pooled waves of the European Values Study (EVS) covering the period 1999-2017 to which it applies the linear decomposition technique and multivariate statistical analysis. The results show that, even though the work ethic decreased in the Czech Republic and increased in Slovakia, intergenerational population replacement contributed to its weakening in both countries. Furthermore, the results indicate that the reason this process dominated the overall trend in the Czech Republic but not that in Slovakia may be the historical differences in levels of socioeconomic development and the different paces of population replacement. Finally, tentative evidence in favour of modernisation theory is presented, indicating that population replacement universally contributed to a decrease in the work ethic in all the other European countries with comparable EVS data.
\end{abstract}

Keywords: work ethic, work orientations, modernisation theory, linear decomposition, European Values Study.

Sociologický časopis/Czech Sociological Review, 2020, Vol. 56, No. 6: 741-765

https://doi.org/10.13060/csr.2020.049

\footnotetext{
* Acknowledgement: This article is based on research conducted by the author during his visiting research fellowship at the Comenius University in Bratislava, which was supported by the Utrecht Network Young Researchers Grant. The manuscript was finalised during the author's research stay at the University of North Carolina at Chapel Hill, supported by the J. W. Fulbright Commission for Educational Exchange in the Slovak Republic. Arne L. Kalleberg, Hans-Tore Hansen, and Ole Johnny Olsen deserve a special mention for their insightful comments on an earlier version of the draft. Thanks to the two anonymous reviewers for their highly constructive feedback.

** Direct all correspondence to: Michal Kozák, Department of Sociology, University of Bergen, Postboks 7802, 5020 Bergen, Norway, e-mail: Michal.Kozak@uib.no.
} 


\section{Introduction}

In recent decades, modernisation theory ${ }^{1}$ has established itself as a prominent theoretical framework for the analysis of value change in advanced industrial societies. Despite its popularity, surprisingly little attention has been paid to the implications of the post-materialist value shift in the realm of work. However, work values and the work ethic in particular play a crucial role in Inglehart's conception of social and cultural change. Modernisation theory asserts that the work ethic is an important cultural component in the first phase of the modernisation process, as it disrupts cultural norms concerning accumulation and opens the way for industrialisation and capitalism [Inglehart 1997; Inglehart and Welzel 2005]. However, being essentially a system of materialistic values, the work ethic is expected to gradually weaken during the post-industrial phase of modernisation, as continuing material prosperity shifts the value preferences of newer cohorts in a post-materialist direction [Norris and Inglehart 2011]. The evidence as to whether such a trend is indeed taking place in advanced industrial societies remains rather inconclusive. So far, only a few studies have examined the implied negative relationship between the work ethic and development, and very few of these have done so from the dynamic perspective of social change [Dülmer 2011; Norris and Inglehart 2011; Stam, Verbakel and De Graaf 2013].

This paper attempts to fill the gap in the empirical literature and offers an analysis of the time trend in relation to the work ethic in the Czech Republic and Slovakia, two dynamically developing and culturally similar Central European countries. The study uses three pooled waves of EVS data covering a period of 18 years, from 1999 to 2017, and applies descriptive analysis together with linear decomposition and multivariate statistical analysis.

The study has two specific goals. First, the exploratory goal is to analyse trends in the work ethic in the two societies, compare them, and provide possible explanations for the observed differences. The second goal is to test a theory. The study seeks to determine the extent to which the work ethic in the two countries has changed in line with the expectations of modernisation theory, that is, whether it has declined proportionally to the growth in material prosperity, whether the decline has been primarily driven by the intergenerational replacement of the population, and to what extent observed patterns of change can be generalised to other European countries.

\footnotetext{
${ }^{1}$ More specifically, the study draws upon the theory of values modernization developed by Inglehart and his colleagues [Inglehart 1997; Inglehart and Welzel 2005]. Despite various criticisms, the framework is widely recognized among the most prominent approaches to cultural modernization in present-day sociology and political science [Haller 2002]. Later in the text, the framework is simply referred to as modernization theory. However, modernization theory is a broad research field within the sociology of development, with a long history and a number of specific sub-fields and contributors [Marsh 2014].
} 
The article is structured as follows. First, the theoretical premises of modernisation theory as it relates to the work ethic are outlined. Second, the cases of the Czech Republic and Slovakia are examined and compared, mostly with respect to their standing in the modernisation process and socioeconomic development. Third, the hypotheses are formulated, after which the paper continues with a description of the data and the measures for the variables. The empirical analysis starts with an examination of how the work ethic changed between 1999 and 2017. It continues by identifying the proximate sources of the change through linear decomposition and multivariate statistical analysis, before ending by comparing the Czech and Slovak results with nine European countries. The paper concludes with a discussion of the similarities and differences between the Czech Republic and Slovakia and of the relevance of the modernisation theory framework to work orientation research.

\section{Theory}

\section{Modernisation theory and the work ethic}

The basic premise of modernisation theory is that socioeconomic development brings about predictable and coherent patterns of change in political and cultural life, which unfold in two distinct phases [Inglehart and Welzel 2005: 25]. In the industrial phase, bureaucratisation and secularisation emphasise secular-rational values. Economic strategies are centred on the maximisation of material output, while individuals' value preferences underline physical and material security. Diminishing returns from economic growth mark the post-industrial phase of modernisation. At the level of economic strategies, a fundamental shift occurs towards a maximisation of well-being through lifestyle changes. In the cultural realm, this phase is characterised by the evolution of post-materialist values, which means a general shift in people's worldview towards an emphasis on autonomy, selfexpression, and quality of life [Inglehart 1997: 28]. This value transformation is considered to proceed in accordance with two principles [Inglehart 1997: 33-36; Inglehart and Welzel 2005: 97-99]. First, the 'scarcity hypothesis' assumes that people are more likely to emphasise post-materialist values under conditions of prosperity, while conditions of scarcity are conducive to materialistic preferences. Although preferences such as autonomy and freedom are universal to all humans in all historical periods, they become goals of primary importance only insofar as material sustenance is achieved. Second, the 'socialisation hypothesis' stipulates that the relationship between prosperity and post-materialism requires a substantial time lag of 10-15 years to manifest. It occurs gradually through intergenerational population replacement as younger cohorts replace the older ones. This is because basic personality values are predominantly shaped by conditions and experiences from one's pre-adult formative years. While the intergenerational differences are supposed to reflect long-term socioeconomic changes rather than 
life-cycle effects, their impact on cultural change can be temporarily swamped by short-term situational period effects [Inglehart and Welzel 2005: 94-99].

What role does the work ethic play in the value change process and how is it affected by the onset of post-materialism? According to Norris and Inglehart [2011], the work ethic is essentially a materialistic value system, which encourages economic accumulation as something heroic and laudable and is conducive to an emphasis on economic growth. Like other materialistic values, the work ethic is common to societies marked by material scarcity and is inclined to fade away in conditions of prosperity [Inglehart 1997: 218; Norris and Inglehart 2011: 161-162]. Whilst the work ethic contributed to the creation of a 'cultural-economic syndrome', which gave way to capitalism and the Industrial Revolution, the post-materialist value shift in some ways constitutes its decline [Inglehart 1997: 27-28]. When work is no longer perceived as an existential necessity, people turn to other opportunities for self-development [Norris and Inglehart 2011: 164]. In other words, modernisation theory expects post-materialism and the work ethic to be inversely related to socioeconomic development, and thus negatively related to one another. Therefore, just as prolonged periods of economic growth should be conducive to the spread of post-materialism, they should also result in a decline in the work ethic. At the same time, however, just as the relationship between post-materialism and development is not one of immediate adjustment, the decline in the work ethic should proceed gradually through intergenerational population replacement. ${ }^{2}$

The available empirical evidence for the negative relationship between development and the work ethic comes mostly from large-scale comparative studies. Comparing findings is complicated, not only because of differences in the way the countries in an analysis are selected, but also because of different definitions of the work ethic [see discussion in Cherrington 1980: 19-21]. Norris and Inglehart [2011: 159-169] tested the assumptions of modernisation theory using the World Value Survey (WVS) and EVS data for the period 1981-2001. At the macro level, they found the work ethic, measured as a duty towards society, to be weakened by levels of human development. At the individual level, the work ethic was found to decrease with education and income, which are indicators of one's economic security. Dülmer [2011] replicated Norris and Inglehart's study [2011] within a multilevel framework and demonstrated that the weakening of the work ethic commences in the earlier stages of modernisation and is not exclusive to its post-industrial phase. He showed that younger cohorts in all societies, irrespective of development, had a weaker work ethic, but the effect of education was dependent on a country's level of development: negative in advanced postindustrial societies and positive in modernising countries. Stam, Verbakel and De

\footnotetext{
${ }^{2}$ Modernization theory is not the only theoretical approach which predicts the erosion of the work ethic in developed societies. Other theories reach similar conclusions, but emphasize the importance of different factors [see the review in Furnham 1990: 201-211].
} 
Graaf [2013] analysed data from the 2008 wave of EVS data for 44 counties and found modernisation to be negatively related to the work ethic, operationalised through the concept of the work ethos. Similar results were reported with respect to the effect of modernisation on work attitudes related to the work ethic. In their study of 26 countries using WVS data, Parboteeah and Cullen [2003] found that the degree of industrialisation is negatively related to work centrality. Analysing International Social Survey Programme (ISSP) data from 25 countries, Parboteeah, Cullen and Paik [2013] showed that post-industrialisation is associated with a general decline in extrinsic and intrinsic work values.

The evidence for generational differences in the work ethic and work orientations in general is slightly less consistent. Here, the results also differ with respect to the use of a particular method. In her comprehensive review, Twenge [2010] concluded that most time-lag and cross-sectional studies confirm a consistent generational trend towards a weaker work ethic, lower work centrality, a higher valuation of leisure, and a stronger emphasis on freedom and work-life balance among more recent generations. However, studies using different models generally fail to find any differences in work values between cohorts. Analysing data from five waves of combined WVS and EVS data using a hierarchical age-period-cohort regression model, Hajdu and Sik [2018a] claimed that birth cohorts in European and Euro-Atlantic countries do not differ significantly with regard to their work centrality and work values and that they are more strongly correlated with age. The same authors [Hajdu and Sik 2018b] reported very similar results in their analysis of employment commitment using ISSP data from 30 countries: no significant differences between cohorts were found. However, the evidence did point to minor effects of period and age. Kalleberg and Marsden [2019] also applied hierarchical age-period-cohort logistic regression to disentangle changes in the values of American workers between 1973 and 2016. They showed that the most widespread differences in work values were related to the historical periods during which people live, rather than to the effects of ageing or cohort differences.

\section{Socioeconomic development in the Czech Republic and Slovakia}

Inglehart argues that, even though the post-materialist value shift produced by development proceeds in a systematic fashion, it is also path-dependent and reflects the influence of a country's unique cultural and historical heritage [Inglehart and Welzel 2005: 18-22]. However, such differences are less relevant to the present study, as the Czech Republic and Slovakia are arguably two countries whose geographical, cultural, and historical proximity has been shaped by almost 70 years of common history within one state, as part of Czechoslovakia. It can be argued that, by focusing on a comparison of the Czech Republic and Slovakia, the study resembles what is referred to as a 'most similar nations' design [Ragin 1987: 47-48], implying that any observed dissimilarities in value orientations between 
the countries are more likely to stem from differences in socioeconomic development than to reflect their cultural, religious, or institutional specificities. Even in Inglehart and Welzel's own study [2005: 56-76], the two countries are categorised within the clusters of predominantly industrial, middle-income societies with a Catholic religious heritage and a communist past. Although the former communist states in Eastern Europe tend to be less post-materialist, previous studies have shown that the value shift has taken place there too, including in the Czech Republic and Slovakia [Rabušic 2000; Savelyev 2016].

However, the Czech Republic and Slovakia differ in their socioeconomic development and historical experiences of modernisation. The Czech Republic has always been the more developed of the two countries as well as being the first to industrialise. The beginning of industrialisation in the Czech Republic dates back to the pre-war period, when the country was still part of the Austro-Hungarian Empire. By contrast, the predominantly agrarian pre-war Slovakia only started to industrialise in the 1930s, when it was already part of Czechoslovakia. Extensive Soviet-type industrialisation took place in both parts of the republic under state socialism and resulted in the equalisation of social and cultural development towards the end of state-socialist rule and the dissolution of the joint state in 1993 [Krejčí and Machonin 1996: 235]. As Figure 1 shows, differences in the levels and pace of socioeconomic development are also detectable when available historical data on gross domestic product (GDP) per capita are analysed. The figure indicates that both societies experienced a continuous increase in GDP in the last three decades, and even though the Czech Republic remains the more developed of the two states, strong growth in Slovakia in recent years has substantially reduced the difference.

If viewed through the lens of modernisation theory, the data can be translated into a set of empirically testable hypotheses. ${ }^{3}$ Given the historical differences in the development between the two societies, one would expect the average work ethic to be weaker in the relatively more affluent Czech society than in the comparatively less prosperous Slovakia (H1). Since both countries have experienced continuous increases in prosperity in the last few decades, a long-term negative trend in the work ethic is expected to be found in both the Czech Republic and Slovakia (H2). Given that these developments have been simultaneously reflected in a steady increase in economic security, intergenerational population replacement is suspected to have contributed to a decrease in the work ethic in both countries (H3). Since the formative experiences of Czech cohorts were presumably obtained under conditions of comparatively higher prosperity, both the

\footnotetext{
${ }^{3}$ Since intergenerational replacement is supposed to affect society's values with a lag of 10-15 years, the hypotheses are based on long-term historical trends rather than solely on dynamics of development during the analysed period. More recent developments are likely to affect value orientations of future cohorts which are not yet fully represented in the data.
} 
Figure 1. GDP per capita (thousands of PPP-adjusted USD) in the Czech Republic and Slovakia 1992-2017

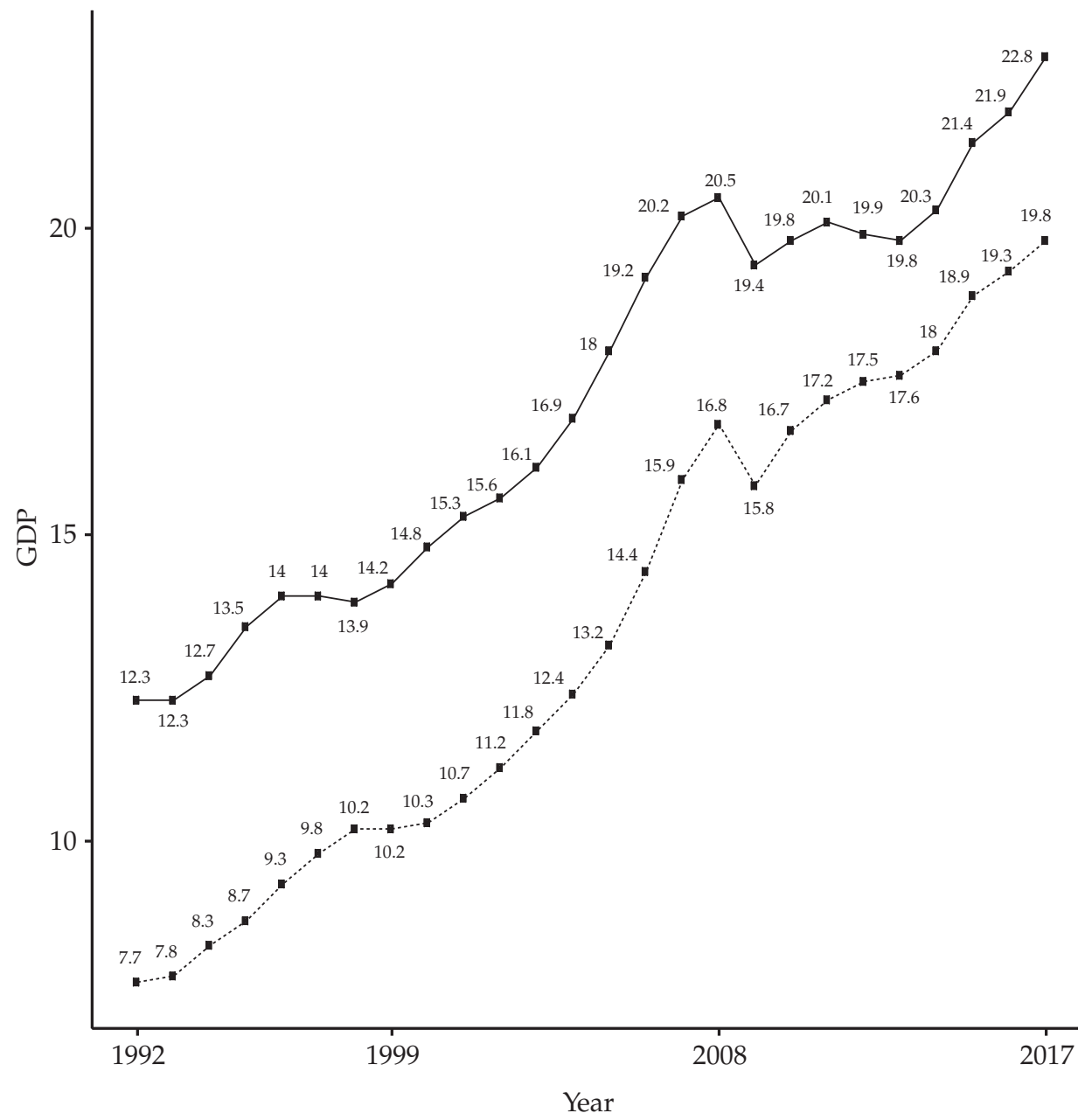

Countries:

- Czech Republic

.... Slovakia

Source: World Bank [2019]. 
overall negative trend and the contribution of intergenerational replacement are expected to be stronger in the Czech Republic than in Slovakia (H4). Finally, if changes in the Czech Republic and Slovakia are two specific examples of a more general pattern of value change taking place in all advanced societies, similar trends should be found in other countries that also experienced economic development (H5).

\section{Data}

The paper employed three different sets of combined data from the 1999, 2008, and 2017 waves of the EVS [2015, 2019]. The first part of the analysis, devoted to describing and decomposing trends in the work ethic in the Czech Republic and Slovakia, used sub-samples from the two countries. After list-wise deletion of the cases with missing values, there were 5414 individuals in the Czech sample and 4229 in the Slovak sample. The second part of the analysis, which used multivariate statistical methods, drew upon the same data but included a few additional predictors. Since this also meant an increase in missing data, the R package 'mice' [van Buuren and Groothuis-Oudshoorn 2011] was used to minimise potential biases. Five data sets were imputed, and whilst all the predictors and the outcome were part of the imputation model, missing values were imputed only for the additional predictors. The third part of the analysis, which placed the Czech and Slovak results in a comparative context, used analogical sub-samples for another nine countries with comparable EVS data. These countries were (in alphabetical order): Bulgaria, Croatia, Denmark, Germany, the Netherlands, Poland, Russia, Slovenia, and Spain.

\section{Methods}

The paper primarily relies on linear decomposition, a method designed for analysing sources of social change using repeated cross-sectional data [see Firebaugh 1989: 252-253; 1997: 25-29; 2010: 805-811]. The method is based on the following idea: shifts in public opinion over time may occur because individuals actually change their opinions and/or they may stem from changes in the composition of the population, where the attitudes of new cohorts differ from those of the cohorts being replaced. This method applies a cohort-by-period design and employs regression to disentangle the change in some aggregate attributes of society into the part of it that is due to the aggregated individual change that occur within cohorts over time (within- or intra-cohort change) and the part of it that is due to the effect of cohort replacement (cross- or inter-cohort change). There are three steps to this method.

In the first step, data from all cross-sections are pooled and the outcome variable is regressed on the survey year and the respondent's birth year, which 
indicates cohort membership [Firebaugh 1989: 253]. The coefficient for year reflects the average annual change in the outcome variable within cohorts, while controlling for cohort differences. Analogously, the cohort coefficient captures the average difference in the outcome between subsequent cohorts, while keeping the year constant. In the second step, these coefficients are used to calculate the contribution each component makes to the overall social change. To obtain the total contribution of aggregated individual change, the year coefficient is weighted by the number of years that have passed between the first and last waves of the survey. The total contribution of the cross-cohort change is calculated in a similar way, multiplying the cohort coefficient by the difference between the average birth year of respondents in the first and the last cross-section. As the technique is based on the assumed linearity and additivity of the two components, the third step aims to check whether the assumptions hold by summing the two components and dividing them by the actual change observed in the data. Owing to non-linearities and interaction, the ratio rarely equals exactly one, but the discrepancies should not be large [Firebaugh 1997: 25].

It is important to note that the decomposition method does not resolve the identification problem of separating age, period, and cohort. These are perfectly correlated in any given data set and to discern them without a theoretical assumption is mechanically impossible [Bell 2020]. Nevertheless, the decomposition of trend data into two orthogonal components reflecting aggregated individual change (which may result from age and/or period) and cohort replacement (where cohort differences might be due to age and/or cohort) is feasible [Alwin and McCammon 2003: 33-34] and has been successfully performed in a number of studies on attitudinal change [Brewster and Padavic 2000; Kalleberg and Marsden 2013; Kraaykamp 2012; Savelyev 2016].

Some argue that decomposition is meaningful only when the effect of age on the dependent variable is absent [Glenn 2005: 36]. Where such an assumption holds, two components of change can be interpreted as reflecting the effects of cohort (inter-cohort trend) and period (intra-cohort trend) [Alwin and McCammon 2003: 34]. Even though decomposition is not dependent on this premise, it seems plausible that the effect of age does not substantially confound the results of the linear decomposition in this study. Along with the theoretical argument about intergenerational differences being resistant to changes over the life course, there is also tentative empirical evidence of this from longitudinal panel studies. These studies found no straightforward indication that age or maturation affects work attitudes such as job involvement [Wille et al. 2014] or work centrality [Sharabi and Harpaz 2007]. They showed that work values tend to stabilise with age and change as a function of job rewards [Johnson 2001].

Since the goal of linear decomposition is to approximate sources of social change, the method is supplemented with multivariate statistical analysis in an attempt to investigate the mechanisms behind the trends. 


\section{Variables}

\section{The dependent variable}

Starting from the 1999 wave, the EVS includes a battery of five items that are supposed to capture the 'work ethos', which is defined ${ }^{4}$ as the 'strength of the social norm that places a positive moral value on doing a good job' [EVS n.d.].

The EVS respondents are required to express the degree to which they agree with the following five statements:

1) To fully develop your talents, you need to have a job.

2) It is humiliating to receive money without having to work for it.

3) People who do not work become lazy.

4) Work is a duty to society.

5) Work should always come first, even if it means less spare time.

Responses, originally recorded on a 1-5 scale, are reverse-coded so that the scale increases in the direction of stronger agreement with a given statement and is anchored to the variants 'strongly disagree' (value 1) and 'strongly agree' (value 5).

Even though the EVS implicitly suggests that all the items constitute a onedimensional scale, Norris and Inglehart [2011: 163] argue that attitudes towards work as a duty, which 'lie at the heart of ascetic forms of Protestantism', are best captured by items $2-4$. Because of these conflicting opinions, the dimensional structure was inspected before the composite scale was constructed. Multiple conventional methods confirmed the one-dimensional structure to be optimal. The factor analysis subsequently conducted with principal axis factoring showed that all the items loaded sufficiently well on one factor. This explained $38 \%$ of the items' variance in the Slovak sample and $37 \%$ in the Czech sample ${ }^{5}$ (see Table A1 in the appendix). The composite scale was thus constructed by aggregating scores across all five items ${ }^{6}$ (an alpha reliability of 0.74 in the Czech sample

\footnotetext{
${ }^{4}$ The origin of the concept can be traced back to Weber [1958]. Weber understood the Protestant work ethic as a broad philosophy of life related to religious and economic activity, which contributed to the creation of a specific cultural ethos necessary for the establishment of capitalism as the dominant economic system in the Western world. However, most contemporary studies, including Inglehart's study and the study presented here, are based on a narrower definition of work ethic, conceptualized as a non-religious set of positive attitudes about work and its importance [Cherrington 1980: 19].

5 Additionally, results from a series of multigroup confirmatory factor analysis models indicated the presence of strict factor invariance, thus rendering comparison of the construct in the Czech and the Slovak context possible.

6 The scale was constructed for respondents who provided answers for at least three items. Scores were adjusted for the total number of answered items.
} 
and 0.75 in the Slovak sample). To enhance interpretability, the scale was further transformed into a simple intensity index, ranging from 0 to 100 . The scores can thus be interpreted in a more intuitive way, as percentages of a theoretically maximal work ethic score.

\section{The independent variables}

Two different sets of predictors were used in the analysis: one set for the part of the analysis that uses linear decomposition, and another set for the part which corroborates the findings with multivariate methods.

In addition to the outcome variable, linear decomposition only required the predictors for survey year and birth year. The survey year variable was coded as the year when the survey was conducted, centred at the first EVS wave, in 1999. The birth year or cohort variable was obtained by subtracting the respondent's age from the year of the survey. This variable is centred at the birth year of the oldest cohort, 1911 in the Czech Republic and 1913 in Slovakia.

The models used in the part of the analysis intended to corroborate the findings estimated the work ethic in a stepwise fashion as a function of the survey year, cohort, and a set of additional predictors and controls. Since the direct effect of development measured at the country level cannot be reliably estimated within a given comparative design, the models controlled for individual-level characteristics known to be indirectly associated with socioeconomic development, together with controls for gender and marital and employment status. Economic resources, as the most tangible effect of development, were captured by a continuous variable for income, which was derived from the interval midpoints of the original EVS income variable. The values for both countries were converted to thousands of euros per month adjusted by purchasing power parity [Eurostat 2019]. Increasing educational attainment is considered another central component of modernisation. Since people from a more affluent background tend to have higher levels of education, this reflects people's cognitive autonomy and their material security during their formative years [Abramson and Inglehart 1996]. The predictor for education was measured as the age at which the respondent completed formal schooling. Gender was controlled for using a binary variable with a value of 1 assigned to women and a 0 to men. Marital status was captured with a set of dummies for married individuals, singles, people who are divorced or separated, and people who are widowed. Employment status was measured in a similar way, distinguishing between respondents who were employed, unemployed, retired, and students and others not active in the labour force. Importantly, the last two controls are related to some of the main age-related life-course transitions. Thus, their inclusion in the model can indicate to what extent the results are confounded by age. This could not be directly estimated within the decomposition framework (cf. with the approach in Kraaykamp [2012]). 
Table 1. Change in average work ethic scores, 1999-2017

\begin{tabular}{lcccc}
\hline \multirow{2}{*}{ Country } & \multicolumn{4}{c}{ Work ethic score (0-100) } \\
\cline { 2 - 5 } & 1999 & 2008 & 2017 & $\Delta$ 2017-1999 \\
\hline Czech Republic & 67.59 & 64.84 & 65.26 & -2.33 \\
Slovakia & 68.58 & 70.30 & 72.37 & 3.79 \\
\hline
\end{tabular}

\section{Results}

\section{Descriptive results}

Table 1 presents the average scores for the work ethic index for each wave of EVS data. The last column shows the direction and magnitude of the change, calculated as the difference between the scores from the first and the last waves. The table suggests that, in spite of the similarities in cultural heritage and socioeconomic development, the work ethic in the Czech Republic and Slovakia changed in opposite directions. Whilst in the Czech Republic the work ethic weakened between 1999 and 2008 and remained approximately at the same level until 2017, it was continuously increasing over the same period in Slovakia. In absolute terms, the magnitude of the change was higher in Slovakia where the work ethic increased by $3.79 \%$, whilst in the Czech Republic it decreased by $2.33 \%$. With respect to the relative position of the two countries, Slovakia had a consistently stronger average work ethic than the Czech Republic in each of the three waves. However, diverging trends strengthened the initial difference, so that it was more than seven times larger in 2017 than in 1999.

Taken together, the findings provide a mixed picture with respect to the expectations derived from modernisation theory. Whilst a relatively weaker work ethic with a negative long-term trend, like that observed in the Czech Republic, appears to be fully in line with the theoretical logic ( $\mathrm{H} 1$ and H2), the strengthening of the work ethic in Slovakia is rather puzzling. Still, the results do not necessarily contradict the key expectation of modernisation theory regarding the negative effect of intergenerational differences in the work ethic. It may be that population replacements contributed to a decrease in the work ethic in both countries, but the overall trends were shaped by country-specific situational effects that affected the attitudinal conversion of all individuals and temporarily pushed the trends in opposing directions.

\section{Linear decomposition}

A linear decomposition of work ethic trends was used to investigate how intergenerational replacement contributed to the observed changes in the work ethic in the Czech Republic and Slovakia. In the first step, the work ethic in each coun- 
Table 2. Estimated effects of year and cohort on the work ethic, 1999-2017

\begin{tabular}{lcc}
\hline & Czech Republic & Slovakia \\
\hline Year & $0.09^{*}$ & $0.31^{* * *}$ \\
Cohort & $-0.26^{* * *}$ & $-0.17^{* * *}$ \\
Observations & $5414^{* *}$ & 4229 \\
$\mathrm{R}^{2}$ & 0.067 & 0.028 \\
\hline
\end{tabular}

Note: statistical significance $={ }^{*} \mathrm{p}<0.05,{ }^{* *} \mathrm{p}<0.01,{ }^{* * *} \mathrm{p}<0.001$.

try was regressed on survey year and cohort year predictors (see Table 2). The positive sign for the survey year coefficient (intra-cohort change) that was found in both countries shows that the work ethic of an average individual was, year by year, increasing in both the Czech Republic and Slovakia. At the same time, the negative signs for the cohort year coefficient (inter-cohort change) indicate that in both countries the work ethic of each successive birth cohort was weaker than that of its predecessor. When the magnitude of the two effects is assessed, one sees that the intra-cohort effect is the stronger of the two effects in Slovakia, while in the Czech Republic, the cohort replacement effect is stronger.

To quantify the relative contribution of the two sources, namely cohort replacement and intra-cohort change, to the overall change, the year coefficient was multiplied by the number of years that had elapsed from the first to the last survey wave, and the cohort coefficient was multiplied by the average difference in birth year means between the first and the last wave. The first of these two numbers was the same for both countries - 18 years had passed between 1999 and 2017. The pace of the cohort turnover was country-specific and amounted to 14.3 years in the Czech Republic and 10.6 years in Slovakia.

Table 3 displays the results of the linear decomposition of work ethic changes in the Czech Republic and Slovakia. It shows that the decline in the work ethic in the Czech Republic was primarily due to cohort replacement. If the overall trend was only shaped by a weakening work ethic among younger cohorts, the decline would have been even steeper at 3.79\%. However, the effect was mitigated by ag-

Table 3. Decomposition of the change in the work ethic, 1999-2017

\begin{tabular}{lcc}
\hline & Czech Republic & Slovakia \\
\hline Change in the work ethic, 1999-2017 & -2.33 & 3.79 \\
a) Within-cohort change contribution & 1.57 & 5.60 \\
b) Cohort-replacement effect contribution & -3.79 & -1.77 \\
Predicted/observed change & 0.95 & 1.01 \\
\hline
\end{tabular}


gregated attitudinal change, which would alone have resulted in an increase in the work ethic by $1.57 \%$. Since the latter component was only half the size of the former, the average work ethic in the Czech Republic declined. In Slovakia, the strengthening of the work ethic, generated by aggregated attitudinal change, outweighed the negative effect of the inter-cohort change. Whilst the within-cohort change alone would have resulted in an increase in the work ethic by $5.6 \%$, cohort replacement would have led to a decrease of $1.77 \%$. As the former component was much larger, the result was an overall increase in work ethic. ${ }^{7}$ Finally, the last row of the table shows that the linear decomposition estimates are fairly precise and that the linear and additive effects explain most of the observed trends in both countries.

These results indicate that the difference in work ethic trends between the Czech Republic and Slovakia conceals a remarkable similarity in terms of the mechanism that generates them. The difference in work ethic trends stem primarily from the difference in the strength of the components of change, not from their different effects. As expected, intergenerational population replacement contributed to the decrease in the work ethic in both countries (H3) and its negative contribution was stronger in the Czech Republic than in Slovakia (H4). However, this is not entirely the result of intergenerational differences. At least part of its stronger contribution reflects a more dynamic pace of cohort turnover, which amplified the comparatively lower work ethic among more recent $C$ zech cohorts. On the other hand, population replacement in Slovakia proceeded at a much slower pace and newer cohorts were unable to shape society's values to the same extent as they did in the Czech Republic. Moreover, intra-cohort attitudinal change contributed to an increase in the work ethic in both countries, but its contribution was much greater in Slovakia. One can only speculate about the extent to which this was a country-specific period effect.

In summary, the question as to why the work ethic increased in Slovakia and decreased in the Czech Republic can be reformulated into two specific questions: Why was there a much stronger positive intra-cohort trend in Slovakia than in the Czech Republic? Why is the work ethic of younger Czech cohorts so much weaker than that of their Slovak counterparts?

\section{Multivariate analysis}

In the last step, the work ethic was regressed on predictors of the intra- and intercohort component of the trend as well as on the other variables associated with positive effects of socioeconomic development and compositional controls (Ta-

\footnotetext{
7 As a robustness check, each individual item of the disaggregated work ethic scale was decomposed in a similar fashion. The results showed that cohort replacement contributed to a decrease in the agreement with every single work ethic item in both the Czech Republic and Slovakia. Differences between the two countries resulted primarily from the differing effects of aggregated attitudinal change.
} 
ble 4). This was done in a stepwise fashion for the Czech Republic and Slovakia separately. The models with an A prefix are the same as those used in the first step of the linear decomposition and serve as a baseline against which the effect of additional predictors is compared. The models with a $\mathrm{B}$ prefix add the predictors related to material security, education, and income. In the models with a $\mathrm{C}$ prefix, respondents' gender and marital and employment status are controlled for.

Looking first at the Czech results, Model 'B - CZ' shows that neither education nor income has an effect on the work ethic. The negative sign for the two coefficients suggests that, had there been any effect, it would have been in the expected direction and reduced the work ethic. The increase in the year coefficient in comparison with Model 'A - CZ' indicates that respondents in later EVS waves have higher educational attainment and better incomes. Were it not for increasing education and income, there would have been an even bigger increase in the work ethic of average individuals. Model ' $\mathrm{C}-\mathrm{CZ}$ ' shows that women have a comparatively stronger work ethic than men and that single and divorced respondents have a weaker work ethic than those that are married. With regard to employment status, it is only the unemployed and others not active in the labour force, whose work ethic is weaker than that of working respondents. When compositional differences are controlled for, the cohort coefficient decreases, suggesting that there is a higher prevalence of social categories with a lower work ethic among more recent cohorts (such as single respondents and/or those with weaker labour market attachment). Furthermore, once controls are included in the model, the negative effect of income increases and becomes significant.

The same models in Slovakia show slightly different results. Model 'B - SK' shows that material security is related to the work ethic in the opposite direction to what was expected: higher incomes and education are associated with a significantly stronger endorsement of the work ethic. When controlled for, the year coefficient drops by almost one-quarter of its initial size, suggesting that a sizeable part of the intra-cohort change is driven by an increase in material security. Interestingly, an increase in the magnitude of the cohort coefficient suggests that higher educational attainment and increasing incomes actually contributed to a decrease rather than an increase in inter-cohort differences. Finally, Model ' $\mathrm{C}-$ $\mathrm{SK}^{\prime}$ indicates that women have a stronger work ethic than men and that the work ethic of married Slovaks is stronger than that of their single or widowed counterparts. Employment status plays a role, too, and the unemployed and other individuals outside the labour force have a significantly lower work ethic than the employed. Interestingly, controlling for gender, marital, and employment status explains away the effect of income and reverts back to a substantial amount of the intra-cohort effect explained in the previous step. The model seems to indicate that the part of the positive intra-cohort trend in Slovakia that is explained by higher incomes may actually be caused by compositional changes connected to the growth of employment and to a decrease in the number of respondents with a weaker labour market attachment. Like in the Czech case, compositional differences account for a small part of inter-cohort differences in Slovakia, too. 


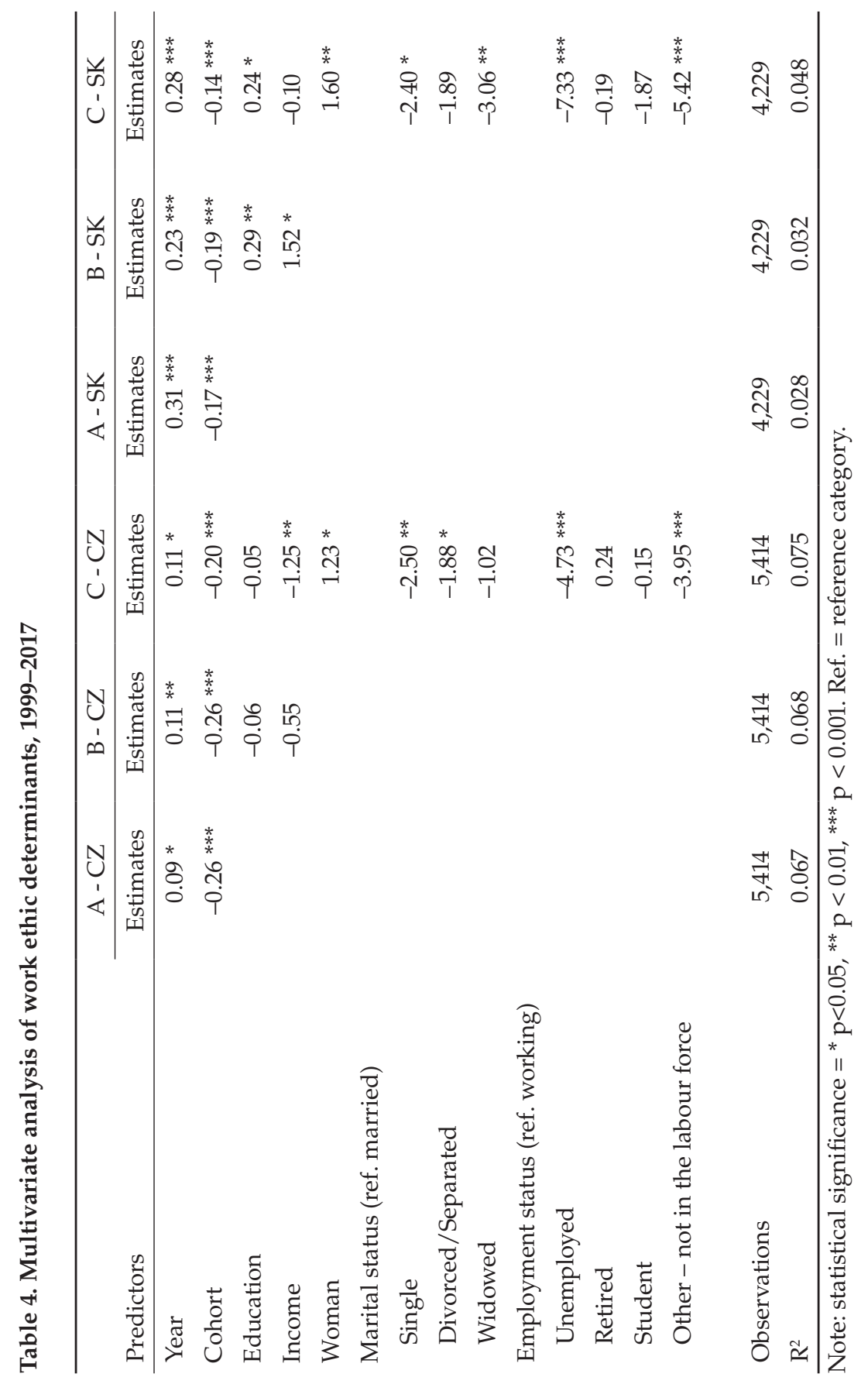


In summary, the models showed that the linear decomposition results are fairly robust and hold true when estimated together with predictors relating to some of the main effects of socioeconomic development and compositional controls. This is less surprising with respect to the inter-cohort component of the trend, since these generational differences are assumed to reflect people's economic security during their formative years rather than their current economic security. Such results further indicate that the work ethic of younger Czech cohorts is likely to be determined by historical differences in prosperity levels between the two countries, translated into differences in material security as experienced during pre-adult years $(\mathrm{H} 4)$.

The intra-cohort trend turned out to be sensitive to the inclusion of development-related predictors, although differently in each country. Dülmer [2011] pointed out that increasing material security should contribute to a weakening of the work ethic only after societies enter the post-industrial stage of their development. In industrial societies, further development should be associated with a strengthening work ethic. Seen from this perspective, it is likely that Slovakia's historically lower level of economic development is translating recent gains from economic growth into strong positive intra-cohort trends. Such a process does not seem to be taking place in the comparatively more developed Czech society.

Last, but not least, the results showed that the work ethic is more consistently connected to a person's economic resources (i.e. having a job or not) and needs (i.e., having a partner or not) than to specific stages in the life course. Since the inclusion of such compositional controls made only a small difference to the decomposition results, it does not seem likely that they were substantially confounded by ageing or life cycle effects.

\section{Cross-national comparison}

The final step is to analyse the extent to which trends in the work ethic observed in the Czech Republic and Slovakia are representative of a more general pattern of work ethic change in the context of modernisation. Table 5 presents the results of a series of linear decompositions of the work ethic in the Czech Republic and Slovakia and another nine European countries with available EVS data for the period 1999 to 2017. The results are presented in ascending order according to the magnitude of overall change. It is important to keep in mind that the results are not directly comparable and should only be regarded as illustrative. This is because countries differ with respect to their cultural and historical heritage, and it is unclear how these differences affect overall trends or their components. Moreover, the uneven pace of cohort replacement and the differences in the degree to which the linearity and additivity assumptions behind linear decomposition are satisfied in each case, complicate the comparison even further. The table reveals that, between 1999 and 2017, the work ethic decreased in seven countries, while 
Table 5. Decompositions of change in the work ethic in 11 European countries, 1999-2017

\begin{tabular}{lcccc}
\hline \multicolumn{1}{c}{ Country } & $\begin{array}{c}\text { Change in } \\
\text { the work ethic, } \\
\text { 1999-2017 }\end{array}$ & $\begin{array}{c}\text { Within- } \\
\text { cohort } \\
\text { change }\end{array}$ & $\begin{array}{c}\text { Cohort- } \\
\text { replacement } \\
\text { effect }\end{array}$ & $\begin{array}{c}\text { Predicted/ } \\
\text { observed } \\
\text { change }\end{array}$ \\
\hline Russia & -5.81 & -1.42 & -4.36 & 1.00 \\
Poland & -5.38 & 0.24 & -4.99 & 0.88 \\
Slovenia & -3.68 & 0.25 & -3.85 & 0.98 \\
Czech Rep. & -2.33 & 1.57 & -3.79 & 0.95 \\
Spain & -1.81 & 1.20 & -3.04 & 1.01 \\
Croatia & -0.71 & 2.58 & -2.76 & 0.24 \\
Germany & -0.64 & 1.21 & -2.94 & 2.69 \\
Bulgaria & 3.02 & 5.97 & -3.35 & 0.87 \\
Denmark & 3.29 & 4.99 & -1.54 & 1.05 \\
Slovakia & 3.79 & 5.60 & -1.77 & 1.01 \\
Netherlands & 6.08 & 7.53 & -2.53 & 0.82 \\
\hline
\end{tabular}

four countries experienced an increase. Looking at sources of change, cohort replacement alone was a source of the work ethic weakening in virtually every country, irrespective of the direction of overall change. Similarly, the aggregate attitudinal change contributed to an increase in the work ethic in almost all the countries except for Russia. In countries where the work ethic decreased, it was always as a result of cohort replacement; where it increased, it was driven by within-cohort change. When compared to developments in other European countries, we see that the Czech Republic is a more typical example than Slovakia. The overall decrease in the work ethic driven by cohort replacement overshadowed the effect of aggregate individual change. This was also experienced in Russia, Poland, Slovenia, Spain, Croatia, and Germany, and, as predicted by modernization theory, it seems to represent the typical pattern. An overall strengthening of the work ethic resulting from intra-cohort change is a scenario seen in Slovakia and also in Bulgaria, Denmark, and the Netherlands. Nevertheless, this does not seem to contradict the expectations of modernisation theory. The dominance of the intra-cohort component points to the potential influence of country-specific situational effects, acting as a temporal disturbance from a slower but more stable negative trend due to cohort replacement. We can thus conclude that, despite differences in the magnitude and the pace of change, the decline in the work ethic implied by modernisation theory is slowly taking place across Europe, including in the Czech Republic and Slovakia (H5). 


\section{Discussion and conclusion}

The main aim of this paper was to investigate long-term work ethic trends in the Czech Republic and Slovakia from the perspective of modernisation theory. In particular, the study examined whether the work ethic in the two culturally similar societies decreased over the years of increasing material prosperity, and whether evidence can be found to confirm that this decrease originated primarily as a consequence of intergenerational population replacement. While most existing empirical studies have focused on cross-sectional aspects of the relationship between development and the work ethic, this study looked at the issue from the dynamic perspective of social change. The study applied the linear decomposition technique and multivariate statistical analysis to data from three pooled waves of the EVS covering a period of 18 years from 1999 to 2017.

A number of interesting findings can be reported. Despite similarities in cultural heritage and socioeconomic development, the work ethic increased in Slovakia and decreased in the Czech Republic. Results from the linear decomposition show that this divergence concealed a similarity in the sources from which change in both countries originated. In both the Czech Republic and Slovakia, there was a gradual weakening of the work ethic among younger cohorts (intercohort change), and this process alone contributed to the overall decrease in the work ethic. At the same time, this trend was countered by a strengthening of the work ethic among average Czechs and Slovaks (intra-cohort change), resulting from actual attitudinal change. The divergence of the overall trends reflects the fact that the weakening work ethic among younger Czech cohorts contributed more substantially to the overall trend than in the Slovak case, whilst the work ethic of average Slovaks increased more than that of Czechs. The decomposition and regression analysis results suggest that there are two main reasons why this is the case.

The first reason refers to the historical differences in development between the two societies. Czech society was historically the first to industrialise and modernise [Krejčí and Machonin 1996: 118-122] and is still the more affluent of the two. If these differences were translated into differential experiences of material security during the formative years of socialisation, it seems logical that Czech cohorts growing up in a more affluent context would become more post-materialist and therefore less concerned with work's normative importance. At the same time, these historical differences may have played a role in Slovaks' stronger attitudinal conversion, leading to a higher work ethic. Previous studies have presented tentative evidence that economic development and education might be linked to the work ethic in a curvilinear fashion: leading to a weaker work ethic in more developed, post-industrial societies, whilst being associated with a stronger work ethic in less developed societies [Dülmer 2011]. The multivariate results showed that this mechanism might be at play in the present study, where gains in material security were associated with a stronger work ethic in the comparatively less developed Slovakia. Here, such gains explained the substantial share 
of the intra-cohort effect, while having no such effect in the more affluent Czech Republic.

The second explanation for the divergence in overall trends is the different pace of cohort turnover in Czech and Slovak society. Not only was the work ethic among younger cohorts in the Czech Republic much weaker than in Slovakia, but the cohort turnover process also proceeded much faster in the Czech Republic. This means that the composition of the Czech population changed more substantially and that the post-materialist attitudes of younger cohorts towards the importance of work shaped society's values to a greater extent.

The study also demonstrated that the population replacement contributed to a decrease in the work ethic in all the European countries for which comparable EVS data were available. Despite the observed differences in the direction of the work ethic trends, the theoretical logic of modernisation theory appears to operate universally: all countries experienced cohort turnover as a negative effect that contributed to a weakening of the work ethic, and, with the exception of Russia, intra-cohort attitudinal change as a positive effect contributing to a stronger endorsement of the work ethic. The discrepancies in overall trends show that an interval of 17 years might not be long enough to demonstrate the effect of slow and cumulative value change brought about by intergenerational population replacement. These results also suggest that the post-materialist value shift has important implications for value changes in the realm of work. Modernisation theory can therefore serve as a useful conceptual framework for the analysis of work orientation values and preferences, not only from a cross-national comparative perspective, but also from a dynamic perspective of social change.

However, the study is not without limitations. The first issue concerns the comparability of the results and stems directly from the use of the EVS's work ethos construct. While commonly used in empirical research to operationalise the work ethic [e.g. van Oorschot 2006; Stam, Verbakel and De Graaf 2013], it differs from Weber's broader notion of the Protestant work ethic [Cherrington 1980] and from the narrower conception of 'work as duty' used by Norris and Inglehart [2011]. These conceptual differences should be treated with caution when comparing results with other studies.

Second, the results have methodological limitations due to the nature of linear decomposition. Whilst it provides useful information as to whether social change is driven by the conversion of individuals' attitudes or by cohort replacement, it does not resolve the age-period-cohort problem and cannot determine where individual and cohort differences come from [Firebaugh 2010].

Future research is encouraged to corroborate the findings presented in this study. A decrease in the work ethic is supposedly only one of the manifestations of post-materialism in the realm of work and the process should be accompanied by a shift in job preferences from 'maximizing one's income and job security towards a growing insistence on interesting and meaningful work' [Inglehart 1997: 44]. Further investigations are required to determine whether this process is tak- 
ing place and whether generational replacement is its primary source. Researchers could also replicate this study in a broader comparative setting using repeated cross-sectional data for a greater number of countries in order to predict the effect of socioeconomic development on the work ethic and its changes over time.

Michal KozÁK is a PhD candidate in the Department of Sociology at the University of Bergen, Norway. His dissertation focuses on work orientations from a comparative perspective.

\section{References}

Abramson, P. R. and R. Inglehart. 1996. 'Formative Security, Education and Postmaterialism: A Response to Davis.' Public Opinion Quarterly 60: 450-455, https://doi.org/10.1086/297764.

Alwin, D. F. and R. J. McCammon. 2003. 'Generations, Cohorts, and Social Change.' Pp. 23-49 in Handbook of the Life Course, edited by J. T. Mortimer and M. J. Shanahan. New York: Kluwer Academic Publishers, https://doi.org/10.1007/978-0-306-48247-2_2.

Bell, A. 2020. 'Age Period Cohort Analysis: A Review of What We Should and Shouldn't Do.' Annals of Human Biology 47 (2): 208-217, https://doi.org/10.1080/03014460.2019.1707872.

Brewster, K. L. and I. Padavic. 2000. 'Change in Gender-ideology, 1977-1996: The Contributions of Intracohort Change and Population Turnover.' Journal of Marriage and Family 62 (2): 477-487, https://doi.org/10.1111/j.1741-3737.2000.00477.x.

van Buuren, S. and K. Groothuis-Oudshoorn. 2011. 'Mice: Multivariate Imputation by Chained Equations in R.' Journal of Statistical Software 45 (3): 1-67, https://doi.org/10.18637/jss.v045.i03.

Cherrington, D. J. 1980. The Work Ethic: Working Values and Values That Work. New York: Amacom.

Dülmer, H. 2011. 'A Multilevel Regression Analysis on Work Ethic.' Pp. 311-340 in Cross-cultural Analysis: Methods and Applications, edited by E. Davidov, P. Schmidt and J. Billiet. New York and Hove: Routledge.

Eurostat. 2019. 'Purchasing Power Parities (PPPs), Price Level Indices and Real Expenditures for ESA 2010 Aggregates [Prc_ppp_ind].' Retrieved 14 October 2019 (https://appsso.eurostat.ec.europa.eu/nui/show.do?dataset=prc_ppp_ind\&lang=en).

EVS. n.d. 'Work'. Retrieved 14 October 2019 (https://europeanvaluesstudy.eu/about-evs/research-topics/work/).

EVS. 2015. 'European Values Study: Longitudinal Data File 1981-2008 (EVS 1981-2008).' GESIS Data Archive, Cologne. ZA4804 Data File Version 3.0.0, DOI: doi.org/10.4232/1.12253.

EVS. 2019. 'European Values Study 2017: Integrated Dataset (EVS 2017).' GESIS Data Archive, Cologne. ZA7500 Data file Version 2.0.0, https:// doi.org/10.4232/1.13314.

Firebaugh, G. 1989. 'Methods for Estimating Cohort Replacement Effects'. Sociological Methodology 19 (1989): 243-262, https://doi.org/10.2307/270954. 
Firebaugh, G. 1997. Decomposing Aggregate Trends In: Analyzing Repeated Surveys. Thousand Oaks, CA: Sage Publications, https://doi.org/10.4135/9781412983396.

Firebaugh, G. 2010. 'Analyzing Data from Repeated Surveys.' Pp. 795-813 in Handbook of Survey Research, edited by P. V. Marsden and J. D. Wright. Bingley: Emerald.

Furnham, A. 1990. The Protestant Work Ethic: The Psychology of Work-related Beliefs and Behaviours. London: Routledge.

Glenn, N. D. 2005. Cohort Analysis. Thousand Oaks, CA: Sage Publications, https://doi.org/10.4135/9781412983662.

Hajdu, G. and E. Sik. 2018a. 'Age, Period, and Cohort Differences in Work Centrality and Work Values.' Societies 8 (1): 1-33, https://doi.org/10.3390/soc8010011.

Hajdu, G. and E. Sik. 2018b. 'Do People Have Different Views on Work by Age, Period and Birth Cohort?' International Journal of Sociology 48 (2): 124-141, https://doi.org/10.1080/00207659.2018.1446117.

Haller, M. 2002. 'Theory and Method in the Comparative Study of Values: Critique and Alternative to Inglehart.' European Sociological Review 18 (2): 139-158, https://doi.org/10.1080/03014460.2019.1707872.

Inglehart, R. 1997. Modernization and Postmodernization: Cultural, Economic, and Political Change in 43 Societies. Princeton, NJ: Princeton University Press.

Inglehart, R. and C. Welzel. 2005. Modernization, Cultural Change, and Democracy. The Human Development Sequence. Cambridge: Cambridge University Press.

Johnson, M. K. 2001. 'Job Values in the Young Adult Transition: Change and Stability with Age.' Social Psychology Quarterly 64 (4): 297-317, https://doi.org/10.2307/3090156.

Kalleberg, A. L. and P. V. Marsden. 2013. 'Changing Work Values in the United States, 1973-2006.' Social Science Research 42 (2): 255-270, https://doi.org/10.1016/j.ssresearch.2012.09.012.

Kalleberg, A. L. and P. V. Marsden. 2019. 'Work Values in the United States: Age, Period, and Generational Differences.' The Annals of the American Academy of Political and Social Science 682 (1): 43-59, https://doi.org/10.1177/0002716218822291.

Kraaykamp, G. 2012. 'Employment Status and Family Role Attitudes: A Trend Analysis for the Netherlands.' International Sociology 27 (3): 308-329, https://doi.org/10.1177/0268580911423046.

Krejčí, J. and P. Machonin. 1996. Czechoslovakia, 1918-92: A Laboratory for Social Change. New York: St. Martin's Press, https://doi.org/10.1057/9780230377219.

Marsh, R. M. 2014. 'Modernization Theory, Then and Now.' Comparative Sociology 13 (3): 261-283, https://doi.org/10.1163/15691330-12341311.

Norris, P. and R. Inglehart. 2011. Sacred and Secular: Religion and Politics Worldwide. New York: Cambridge University Press, https://doi.org/10.1017/CBO9780511894862.

van Oorschot, W. 2006. 'Making the Difference in Social Europe: Deservingness Perceptions among Citizens of European Welfare States.' Journal of European Social Policy 16 (1): 23-42, https://doi.org/10.1177/0958928706059829.

Parboteeah, K. P. and J. B. Cullen. 2003. 'Social Institutions and Work Centrality: Explorations Beyond National Culture.' Organization Science 14 (2): 137-148, https://doi.org/10.1287/orsc.14.2.137.14989.

Parboteeah, K. P., J. B. Cullen and Y. Paik. 2013. ‘National Differences in Intrinsic and Extrinsic Work Values: The Effects of Post-industrialization Cross Cultural Management.' International Journal of Cross Cultural Management 13 (2): 159-174, https://doi.org/10.1177/1470595813485381.

Rabušic, L. 2000. 'Is Czech Society "Post-materialist"?' Czech Sociological Review 36 (1): 3-22, https://doi.org/10.13060/00380288.2000.36.1.02. 
Ragin, C. C. 1987. The Comparative Method: Moving Beyond Qualitative and Quantitative Strategies. Berkeley, CA: University of California Press.

Savelyev, Y. 2016. 'Decomposition of Value Change in European Societies in 1995-2008: Test of Modernization Model and Socialization Hypothesis.' Sociológia 48 (3): 267-289.

Sharabi, M. and I. Harpaz. 2007. 'Changes in Work Centrality and Other Life Areas in Israel: A Longitudinal Study.' Journal of Human Values 13 (2): 95-106, https://doi.org/10.1177/097168580701300203.

Stam, K., E. Verbakel and P. M. De Graaf. 2013. 'Explaining Variation in Work Ethic in Europe.' European Societies 15 (2): 268-289, https://doi.org/10.1080/14616696.2012.726734.

Twenge, J. M. 2010. 'A Review of the Empirical Evidence on Generational Differences in Work Attitudes.' Journal of Business and Psychology 25 (2): 201-210, https://doi.org/10.1007/s10869-010-9165-6.

Weber, M. 1958. The Protestant Ethic and the Spirit of Capitalism. New York: Scribner.

Wille, B., J. Hofmans, M. Feys and F. De Fruyt. 2014. 'Maturation of Work Attitudes: Correlated Change with Big Five Personality Traits and Reciprocal Effects over 15 Years.' Journal of Organizational Behavior 35 (4): 507-529, https://doi.org/10.1002/job.1905.

World Bank. 2019. 'GDP Per Capita (Constant 2010 US\$).' Retrieved 4 September 2019 (https://databank.worldbank.org/reports.aspx?source=2\&series=NY.GDP.PCAP. KD\&country=). 


\section{Appendix}

Table A1. Exploratory factor analysis of work ethic items from the EVS, 1999-2017

\begin{tabular}{lcc}
\hline Items & \multicolumn{2}{c}{ Factor loadings } \\
\cline { 2 - 3 } & Czech Republic & Slovakia \\
\hline Job needed to develop talents & 0.59 & 0.55 \\
People who do not work turn lazy & 0.63 & 0.60 \\
Work is a duty towards society & 0.68 & 0.71 \\
Humiliating - money without working & 0.52 & 0.54 \\
Work always comes first & 0.59 & 0.67 \\
Cronbach's $\alpha$ & 0.74 & 0.75 \\
\hline
\end{tabular}

Table A2. Descriptive statistics for explanatory variables, the Czech Republic

\begin{tabular}{|c|c|c|c|c|}
\hline Variable & Observations & Mean & $\begin{array}{l}\text { Standard } \\
\text { deviation }\end{array}$ & Range \\
\hline Year & 5541 & 2007.84 & 7.37 & 18 (1999-2017) \\
\hline Cohort & 5441 & 1958.70 & 18.60 & 88 (1911-1999) \\
\hline Education & 4650 & 19.08 & 4.11 & $63(7-70)$ \\
\hline Income & 4590 & 1.25 & 0.72 & $4.01(0.12-4.13)$ \\
\hline Woman & 5541 & 0.56 & 0.50 & $1(0-1)$ \\
\hline Married & 5495 & 0.52 & 0.50 & $1(0-1)$ \\
\hline \multicolumn{5}{|l|}{ Marital status } \\
\hline Single & 5495 & 0.21 & 0.41 & $1(0-1)$ \\
\hline Divorced & 5495 & 0.14 & 0.35 & $1(0-1)$ \\
\hline Widowed & 5495 & 0.13 & 0.33 & $1(0-1)$ \\
\hline \multicolumn{5}{|c|}{ Employment status } \\
\hline Working & 5493 & 0.54 & 0.50 & $1(0-1)$ \\
\hline Unemployed & 5493 & 0.04 & 0.19 & $1(0-1)$ \\
\hline Retired & 5493 & 0.31 & 0.46 & $1(0-1)$ \\
\hline Student & 5493 & 0.05 & 0.23 & $1(0-1)$ \\
\hline Other & 5493 & 0.06 & 0.24 & $1(0-1)$ \\
\hline
\end{tabular}

Note: An original uncentred metric for the Year and Cohort variables was used to calculate the reported means. Education is measured as the age at which respondents completed formal schooling. Income is measured in thousands of PPP-adjusted Euros. 
Table A3. Descriptive statistics for explanatory variables, Slovakia

\begin{tabular}{lcccc}
\hline Variable & Observations & Mean & $\begin{array}{c}\text { Standard } \\
\text { deviation }\end{array}$ & Range \\
\hline Year & 4275 & 2008.22 & 7.24 & $18(1999-2017)$ \\
Cohort & 4275 & 1958.74 & 17.58 & $88(1911-1999)$ \\
Education & 4219 & 18.52 & 2.96 & $41(7-48)$ \\
Income & 3384 & 0.99 & 0.67 & $3.55(0.1-3.65)$ \\
Woman & 4275 & 0.58 & 0.49 & $1(0-1)$ \\
Marital status & & & & \\
Married & 4265 & 0.60 & 0.49 & $1(0-1)$ \\
Single & 4265 & 0.18 & 0.39 & $1(0-1)$ \\
Divorced & 4265 & 0.08 & 0.27 & $1(0-1)$ \\
Widowed & 4265 & 0.14 & 0.35 & $1(0-1)$ \\
Employment status & & & & $1(0-1)$ \\
Working & 4269 & 0.53 & 0.50 & $1(0-1)$ \\
Unemployed & 4269 & 0.08 & 0.27 & $1(0-1)$ \\
Retired & 4269 & 0.30 & 0.46 & $1(0-1)$ \\
Student & 4269 & 0.03 & 0.18 & $1(0-1)$ \\
Other & 4269 & 0.06 & 0.23 & \\
\hline
\end{tabular}

Note: An original uncentred metric for the Year and Cohort variables was used to calculate the reported means. Education is measured as the age which respondents completed formal schooling. Income is measured in thousands of PPP-adjusted Euros. 